\title{
An Association Between Psychological Childbirth Trauma and Hazardous Alcohol Use
}

\author{
Michelle Doherty ${ }^{1,2}$ (D) Sally A. Hunt ${ }^{2}$ (D)
}

Accepted: 21 February 2022

(c) The Author(s) 2022

\begin{abstract}
Hazardous alcohol use is increasing amongst some groups of women, yet little is known about the underlying reasons or gender-specific influences. The purpose of this study was to explore the association between psychological childbirth trauma and women's hazardous alcohol use. We aimed to identify predictors of hazardous alcohol use given childbirth-related trauma, other life trauma (combat, natural disasters, physical or sexual assault, experiences threatening loss of life or loss of loved ones) and coping motives for drinking, whilst controlling for age, socio-economic status, negative affect and other drinking motives (enhancement and social motives). Australian data from the Why Women Drink survey $(N=301)$ was analysed. Women who experienced childbirth as traumatic scored higher overall for hazardous drinking and endorsed coping reasons more strongly than those who did not. Analyses of individual differences affecting hazardous drinking revealed coping reasons, rather than trauma itself, as the strongest predictor in a regression model. Other significant predictors included socio-economic status, enhancement of positive emotions and, marginally, negative affect. Findings identified a link between traumatic childbirth and hazardous drinking as a coping strategy. Prospective research is required to characterise predisposing and perpetuating vulnerabilities determining maladaptive coping after traumatic childbirth, and to inform effective interventions.
\end{abstract}

Keywords Alcohol; Hazardous drinking; Coping motives; Childbirth; Psychological childbirth trauma $\cdot$ Trauma

The hazardous use of alcohol has devastating social and economic consequences for both the individual and society (GBD, 2016 Alcohol Collaborators, 2018; Rehm, 2011). Alcohol is responsible for three million deaths, or $5.3 \%$ of total deaths, worldwide every year

Michelle Doherty

m2.doherty@connect.qut.edu.au

Sally A. Hunt

sally.hunt@newcastle.edu.au

1 School of Psychology and Counselling, Queensland University of Technology, Brisbane, QLD 4059, Australia

2 School of Psychology, Faculty of Science, The University of Newcastle, Callaghan, NSW 2308, Australia 
and contributes $5.1 \%$ to the global burden of disease and injury (World Health Organization, 2018).

In Australia, $25.7 \%$ of adult males and $9.9 \%$ of adult females drink at hazardous levels, as defined by the National Health and Medical Research Council (NHMRC) lifetime risk guidelines, with one in four people 'binge' drinking at least once per month, that is, exceeding the NHMRC risk guidelines of not more than four standard drinks on any one occasion, and one in seven doing so weekly (Australian Institute of Health and Welfare, 2020; National Health and Medical Research Council, 2020).

Australian NHMRC guidelines conceptualise hazardous use according to the harm that could arise from alcohol consumption at various quantities and frequencies. These guidelines state that, for healthy adults, drinking no more than ten standard drinks per week reduces the lifetime risk of alcohol-related harm and drinking no more than four standard drinks per occasion reduces the risk of alcohol-related injury on that occasion, where a standard drink contains $10 \mathrm{~g}$ of pure alcohol (Australian Institute of Health and Welfare, 2020; NHMRC, 2020). These guidelines are in line with the World Health Organization's recommended low-risk drinking level of not more than $20 \mathrm{~g}$ of alcohol per day, 5 days per week (Higgins-Biddle and Babor, 2018). In the current study, the term hazardous use is used to refer to levels of drinking exceeding that limit, as distinct from the severe mental health disorders of addiction or alcohol use disorder (AUD). AUD is defined as a problematic pattern of alcohol use, which leads to clinically significant levels of impairment or distress, and which is characterised by a cluster of symptoms that may include craving, tolerance, withdrawal, an inability to control alcohol use, and the continued use of alcohol despite it causing recurrent social, interpersonal, occupational, physical or psychological problems (American Psychiatric Association, 2013).

Historically, men have consumed significantly more alcohol than women and until recently, most interventions or treatments for AUD were developed and tested in a predominantly male population (Agabio et al. 2016; McCrady et al. 2020). However, examination of drinking trends over recent decades suggests that the gender gap in alcohol consumption is closing, in part due to increasing alcohol use by women in younger birth cohorts (Slade et al. 2016). This is concerning particularly as women are more vulnerable than men to the effects of alcohol, due to higher blood alcohol concentrations after equivalent doses of alcohol (Nolen-Hoeksema and Hilt, 2006), and are also at higher risk for alcohol-related diseases such as liver disease, heart disease and breast cancer (Erol and Karpyak, 2015; Freudenheim, 2019; Maddur and Shah, 2019). There is a pressing need to understand the factors underlying problem drinking in certain groups of women, to inform the best possible interventions and most appropriate public health messaging to counter the trend.

Motivational models of alcohol use generally distinguish between social reasons for use, and the phenomenologically distinct behaviour of drinking to regulate emotions (Cooper, 1994; Cooper et al. 1995). The latter comprises both enhancement motives, using alcohol to increase positive mood states or enhance positive emotional experience, and coping motives, whereby alcohol is used primarily as an escape or avoidance mechanism, or to manage stress and other negative emotions. Drinking to cope is the motive most strongly associated with hazardous drinking (Cooper et al. 1992; Grant et al. 2007; Mohr et al. 2018).

Hazardous use of alcohol can be a maladaptive coping response to trauma. There is an accumulated body of evidence demonstrating that exposure to traumatic events, such as natural disasters, physical or sexual assault or combat, is related to the hazardous use of alcohol and that the severity of the trauma may be positively associated with the quantity of alcohol consumed (Cerda et al. 2011; Kachadourian et al. 2014; Ullman et al. 2013). 
At clinical extremes, there is a strong association between post-traumatic stress disorder (PTSD) and AUD (Blanco et al. 2013; Debell et al. 2014; Gilpin and Weiner, 2017). Furthermore, women are more vulnerable than men to developing post-trauma symptoms, are more likely to use emotion and avoidance focused coping strategies and are more likely to start drinking excessively after experiencing trauma (Kachadourian et al. 2014; Olff et al. 2007).

One potentially traumatic event that women are commonly exposed to is childbirth. Yet this event is not explicitly included in any of the standard trauma exposure measures, despite up to half of women reporting a psychologically traumatic birthing experience (Alcorn et al. 2010; O'Donovan et al. 2014), and evidence that a traumatic birthing experience can result in the same PTSD symptoms as those from other traumatic events (James, 2015). Although only around $3 \%$ of women who experienced a traumatic childbirth go on to develop clinical levels of postnatal PTSD (Grekin and O'Hara, 2014), many women experience some post-trauma symptoms after giving birth. More than a quarter of women whose childbirths were deemed medically uneventful report clinically significant levels on at least one PTSD subscale (Ayers et al. 2016).

Given the evidence linking trauma exposure and PTSD symptoms with alcohol misuse, particularly amongst women (Debell et al. 2014; Kachadourian et al. 2014), and that postnatal PTSD is associated with poor coping (Ayers et al. 2016; van Heumen et al. 2018), it is possible that women who experienced psychological trauma during childbirth may subsequently drink alcohol for coping reasons and may therefore be drinking at more hazardous levels than women who did not experience such trauma. If childbirth-related psychological trauma is identified as a driver of hazardous alcohol use, it would indicate an important target for intervention to prevent or treat subsequent alcohol misuse for women who experienced traumatic childbirth.

The aim of this study was therefore to explore the potential association between psychological childbirth trauma and women's hazardous alcohol use. The role of coping motives for drinking and the possible potentiating effect of additional traumatic life experiences were also explored. In considering individual differences, the aim was also to identify the predictors of hazardous alcohol use, given childbirth-related trauma, other life trauma (such as combat, natural disasters, physical or sexual assault or other experiences threatening loss of life or loss of loved ones) and coping motives for drinking, whilst controlling for age, socio-economic status, negative affect and other drinking motives (enhancement and social motives).

\section{Methods}

\section{Procedure and Participants}

This study uses cross-sectional data collected for the 'Why Women Drink' survey, detailed elsewhere (Hunt et al., in preparation), and received ethical approval. Participants were recruited through free and paid advertising on social media platforms (Facebook, Instagram and Twitter) and after providing informed consent, completed an online survey hosted by Survey Monkey (www.SurveyMonkey.com). Survey respondents were female, aged 18 years or over and resident in Australia. As childbirth trauma and alcohol consumption were key variables of interest here, the sub-sample selected for analysis in this study was restricted to women who have ever given birth, who answered questions on the survey 
relevant to perinatal PTSD and who had consumed alcohol within the 6 months preceding the survey $(N=301)$.

\section{Measures}

\section{Demographics}

The following demographic information was collected: age range, country of birth, cultural group or heritage, education level, occupation, employment status, income, marital status, number of children and each child's age. Age, income and education were collected in the survey as categorical variables, following Australian Bureau of Statistics (ABS) categories. They were converted to pseudo-continuous variables for inclusion in the regression analysis. Age and income were determined using the median value of the range corresponding to their categorical values. Level of education was captured in the survey by asking year of high school completed and highest qualification obtained. Approximate number of years of education was calculated using the number of years of school completed and a best estimate in years of any further qualifications obtained. As education and income were moderately correlated $\left(r_{s}=0.42, p<0.001\right)$, a composite socio-economic status (SES) variable was further created, using the mean of the $z$-score standardised education and income variables.

\section{Alcohol Use}

The Alcohol Use Disorders Identification Test (AUDIT; Saunders et al. 1993) was used to assess hazardous drinking levels. Scores of 8 or above on the AUDIT indicate hazardous use of alcohol and possible dependence (Babor et al. 2001). It should be noted that some researchers have recommended lower thresholds of 5 (Neumann et al. 2004) or 6 (Foxcroft et al. 2014) on the total AUDIT score to indicate hazardous drinking amongst women; however, widespread agreement about the optimal value has not been reached.

Motivations for alcohol use were assessed using the 15-item Drinking Motives Questionnaire (DMQ; Cooper et al. 1992). This questionnaire captures different reasons for use related to coping with negative emotions (e.g. 'to forget your worries'), enhancing positive emotions (e.g. 'because it's exciting') and social reasons (e.g. 'it makes a social gathering more enjoyable'). Relative frequency for each of the reasons for use was scored on a scale from 1 to 4 where 1 is almost never/never; 2 is sometimes; 3 is often; and 4 is almost always, following Stewart, Zeitlin and Samoluk (1996).

\section{Trauma}

The Modified Perinatal Post-Traumatic Stress Disorder Questionnaire (PPQ; Callahan et al. 2006) was used to measure post-traumatic symptoms after childbirth, including symptoms of intrusion, avoidance and hyperarousal. The clinical threshold for high risk of postnatal PTSD is a score of 19 or above (Callahan et al. 2006).

Ten other questions on the survey asked about other types of traumatic events an individual may have experienced, such as combat, natural disasters, physical or sexual assault and other experiences which threaten loss of life or loss of a loved one. The Impact of Event Scale-Revised (IES-R; Weiss, 2007) was utilised to assess the effect of those 
traumas. Scores of 24 or higher on the IES-R indicate partial PTSD and scores of 33 or more indicate probable PTSD.

\section{Negative Affect}

The short-form version of the Depression Anxiety and Stress Scales (DASS-21; Lovibond and Lovibond, 1995) was used to measure the degree of depression, anxiety and stress, on separate subscales. As the depression, anxiety and stress subscales of the DASS-21 were all highly inter-correlated (pairwise correlation coefficients 0.55-0.63, see Table 1), the DASS-21 total score was used as a single indicator of negative affect (Henry and Crawford, 2005).

\section{Statistical Analysis}

Data analysis was performed using IBM SPSS Statistics version 25 and all tests were twotailed. Spearman's correlations $\left(r_{s}\right)$ were used to explore bivariate associations, as much of the data did not meet tests of normality.

Independent samples $t$ tests were conducted to compare women who did or did not experience their birth(s) as traumatic on hazardous drinking, as measured by total AUDIT scores; coping motives for alcohol use; and other life trauma. Where Levene's test for equality of variances was significant, equal variances were not assumed and the adjusted $p$ value was used.

A standard multiple regression analysis was conducted to determine whether trauma in general, childbirth-related trauma specifically, and/or coping motives for drinking, predicted hazardous drinking (total AUDIT scores), whilst accounting for covariates of age, socio-economic status, negative affect and enhancement and social drinking motives, which have all previously been associated with drinking habits (Bloomfield et al. 2006; Cooper et al. 1995; Hobden et al. 2017; Kushner et al. 1990; Wilsnack, 2012; Wilsnack et al. 2009).

Most assumptions for a regression analysis were met, with the exception that the residuals deviated moderately from normal and showed some heteroscedasticity. This does not affect the accuracy of the beta weights in the model but may mean that the values are underestimated. To account for that possibility, significance values were calculated using bootstrapped standard errors with 1000 iterations (Erceg-Hurn and Mirosevich, 2008).

\section{Results}

\section{Sample Characteristics}

The sample comprised women who had ever given birth and who had consumed alcohol in the 6 months preceding the survey $(N=301)$. Participants were aged $18-74$ years, $84 \%$ $(n=254)$ were born in Australia and 4\% $(n=12)$ in New Zealand. Most of the respondents were aged over 35 years, with just over half $(51 \%, n=154)$ in the 35-44 age group and the mean time since childbirth was 8.6 years $(S D=4.2)$. More than half of the sample had a tertiary education, with a bachelor, master or doctorate degree $(56 \%, n=168)$ and $82 \%$ $(n=248)$ were in full- or part-time work. The majority of participants were living with a 
partner, either married or de facto $(79 \%, n=239), 12 \%(n=35)$ were previously partnered (separated, divorced or widowed) and 6\% $(n=19)$ were single.

\section{Preliminary Analyses}

A quarter $(25 \% ; n=75)$ of the sample scored in the clinical range for mothers at high risk of perinatal PTSD (19 or higher on the PPQ). Spearman's bivariate correlations, means and standard deviations for study variables are shown in Table 1.

\section{Childbirth Trauma, Alcohol Use and Coping Motives}

Women who had experienced psychological birth trauma had significantly higher total AUDIT scores, $t(98.17)=-2.57, p=.012$, and more strongly endorsed coping motives for alcohol use, $t(107.08)=-3.86, p<.001$, compared to women without such trauma (Table 2). Additionally, they had significantly higher scores for psychological trauma from non-childbirth-related sources, $t(97.64)=-3.89, p<.001)$, although the group mean was still below the clinical threshold indicative of partial PTSD (IES-R $<24$ ).

\section{Multiple Regression}

Overall, the model was significant and accounted for $48 \%$ of the variance in AUDIT scores $\left(R^{2}=.481\right.$, adjusted $\left.R^{2}=.465, F(8,269)=31.11, p<.001\right)$. Regression coefficients, both unstandardised (B) and standardised $(\beta)$, significance values and squared semi-partial correlations for each predictor are shown in Table 3.

The strongest predictor of AUDIT score was coping motives, which accounted uniquely for $7 \%$ of the variance (squared semi-partial correlations; $s r^{2}$ ). Other significant unique predictors were SES (2\%), enhancement motives (2\%) and DASS-21 total score (1\%).

Neither trauma related to childbirth nor trauma related to other events was a significant unique predictor of alcohol use.

\section{Discussion and Conclusion}

Although the link between the experience of trauma and alcohol use is well-established (Blanco et al. 2013; Debell et al. 2014; Gilpin and Weiner, 2017; Kachadourian et al. 2014; Olff et al., 2007), this is the first study, to the authors' knowledge, that specifically examined this link in the context of childbirth. Results from comparison of group means showed that women with psychological childbirth trauma reported drinking at more hazardous levels and more strongly endorsed coping motives for drinking than women without childbirth trauma. When individual differences were analysed as predictors of the variance in hazardous drinking, neither childbirth trauma nor trauma from other sources were significant independent contributors. Rather, coping motives not only independently contributed but was the strongest unique predictor of drinking levels amongst the factors tested. This is consistent with the well-established link between coping motives and problem drinking found in the literature (Cooper et al. 1995; Grant et al. 2007; Hasking et al. 2011; Mohr et al. 2018). Other risk factors previously linked to hazardous drinking were also identified. Socio-economic status, indexed by education and income, was a significant negative 


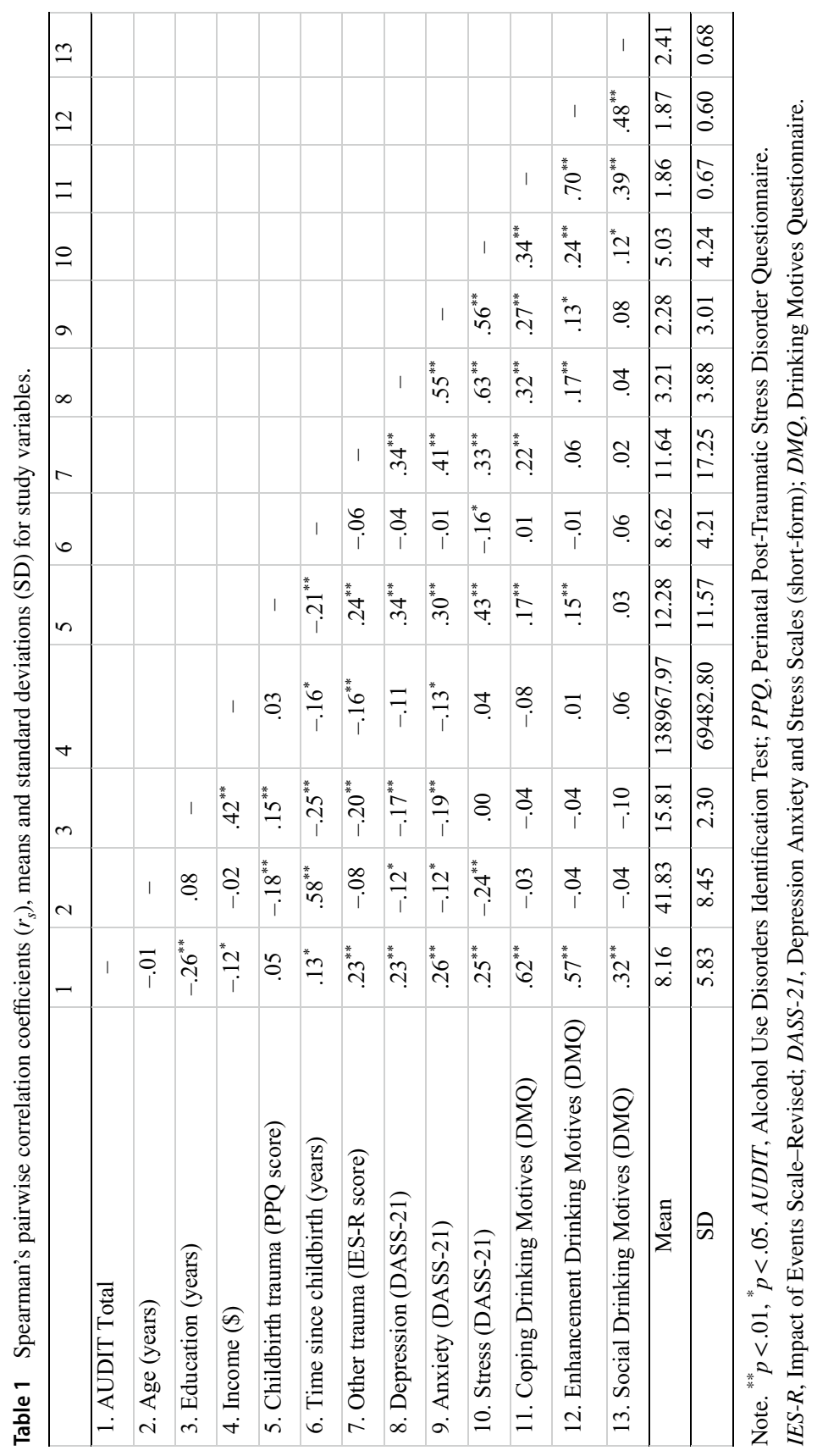


Table 2 Independent samples $t$ tests showing associations between psychological childbirth trauma and alcohol use, coping drinking motives and other life traumas

\begin{tabular}{lllll}
\hline & No childbirth trauma & Childbirth trauma & Test & $p$ value \\
\hline AUDIT total & $7.57(5.09)^{\mathrm{a}}$ & $9.93(7.41)^{\mathrm{b}}$ & $t(98.17)=-2.57$ & .012 \\
Coping drinking motives (DMQ) & $1.77(0.61)^{\mathrm{a}}$ & $2.14(0.77)^{\mathrm{b}}$ & $t(107.08)=-3.86$ & $<.001$ \\
Trauma from other events (IES- & $9.06(15.13)^{\mathrm{c}}$ & $19.36(20.70)^{\mathrm{d}}$ & $t(97.64)=-3.89$ & $<.001$ \\
R) & & & & \\
\hline
\end{tabular}

Note. ${ }^{\mathrm{a}} n=226 .{ }^{\mathrm{b}} n=75 .{ }^{\mathrm{c}} n=215 .{ }^{\mathrm{d}} n=72$. Groups were divided based on scores on the Perinatal PostTraumatic Stress Disorder Questionnaire (PPQ), where no childbirth trauma=PPQ $<19$ and childbirth trauma $=\mathrm{PPQ} \geq 19$. AUDIT, Alcohol Use Disorders Identification Test; $D M Q$, Drinking motives questionnaire; IES-R, Impact of Events Scale-Revised. Scale scores are displayed as mean (standard deviation).

Table 3 Parameters of the best fit multiple regression model predicting the probability of hazardous alcohol use amongst Australian women who have ever given birth $(n=278)$

\begin{tabular}{|c|c|c|c|c|c|c|c|}
\hline Variable & $B$ & CI lower limit & CI upper limit & $\beta$ & $p$ value & $\begin{array}{l}\text { Boot- } \\
\text { strapped } p \\
\text { value }\end{array}$ & $s r^{2}$ \\
\hline Constant & -3.41 & -6.75 & -0.07 & & .046 & .041 & \\
\hline Age & 0.01 & -0.05 & 0.07 & 0.01 & .762 & .768 & 0.00 \\
\hline SES & -1.05 & -1.66 & -0.45 & -0.16 & .001 & .003 & 0.02 \\
\hline $\begin{array}{l}\text { Perinatal trauma score } \\
\text { (PPQ) }\end{array}$ & -0.03 & -0.09 & 0.02 & -0.07 & .180 & .192 & 0.00 \\
\hline Other trauma score (IES-R) & 0.02 & -0.01 & 0.06 & 0.07 & .209 & .323 & 0.00 \\
\hline DASS-21 total score & 0.07 & $\mathbf{0 . 0 0}$ & 0.13 & 0.11 & .043 & .070 & 0.01 \\
\hline $\begin{array}{l}\text { Enhancement motives } \\
\text { (DMQ) }\end{array}$ & 2.29 & 1.02 & 3.56 & 0.25 & $<.001$ & .002 & 0.02 \\
\hline Coping motives (DMQ) & 3.38 & 2.24 & 4.53 & 0.41 & $<.001$ & .001 & 0.07 \\
\hline Social motives (DMQ) & 0.01 & -0.84 & 0.86 & 0.00 & .980 & .979 & 0.00 \\
\hline
\end{tabular}

Note. $N=278$. $B$, unstandardised regression coefficient; $C I$, confidence interval; $\beta$, standardised regression coefficient; $s r^{2}$, squared semi-partial correlations; SES, socio-economic status; $P P Q$, Perinatal PostTraumatic Stress Disorder Questionnaire; IES-R, Impact of Events Scale-Revised; DASS-21, Depression Anxiety and Stress Scales (short-form); $D M Q$, Drinking Motives Questionnaire. Significant predictors are indicated in bold.

predictor of hazardous alcohol use, in concordance with previous studies showing that lower SES related to higher daily alcohol consumption (Yusuf and Leeder, 2015) or to binge drinking (Giskes et al. 2011). Negative affect was strongly associated with the experience of trauma from any source and approached significance as a predictor of hazardous alcohol use, consistent with the high comorbidity between depression/anxiety and alcohol misuse that is already well-documented (Baker et al. 2012; Hobden et al. 2018; Kushner et al. 1990).

The findings presented here indicate that women with childbirth trauma represent a vulnerable group at high risk of misusing alcohol. However, it is not the post-traumatic symptoms per se that are indicative of hazardous alcohol use; more relevant is how an individual copes with the effects of the trauma and/or subsequent life stressors. When identifying and working with groups of women likely to be engaging in hazardous drinking patterns, attention must therefore be paid to their available repertoire of coping skills, which may 
function as a mediator of the effects of trauma and stress on drinking to cope (Merrill and Thomas, 2013; Roos and Witkiewitz, 2016).

Using alcohol to enhance or induce positive emotions (enhancement motives) was strongly linked to coping motives for drinking and also predicted hazardous levels of alcohol use, albeit to a lesser degree. This suggests that another important factor to consider in regards to problem drinking is the capacity to adaptively regulate one's emotions (Simons et al. 2017). Indeed, a critical role for emotional dysregulation has been identified in drinking to cope, at least in samples of young adults (Aurora and Klanecky, 2016; Chandley et al. 2014; Messman-Moore and Ward, 2014). Amongst students exposed to trauma, difficulty with emotion regulation mediated the association between PTSD symptoms and quantity of alcohol consumed (Radomski and Read, 2016). Conversely, teaching coping skills targeted towards distress tolerance and emotion regulation was shown to reduce alcohol consumption in individuals with comorbid AUD and PTSD (Stappenbeck et al. 2015) and a broader repertoire of coping skills may facilitate better alcohol treatment outcomes (Roos and Witkiewitz, 2016). Interventions for alcohol use where coping drinking motives are involved could therefore focus on developing both emotion regulation skills and more adaptive coping strategies.

\section{Limitations}

There are various potential biases within the data. Results from this study may not be generalisable to the broader Australian population, as over half of the sample was tertiary educated, inconsistent with population norms. However, this group is certainly worthy of study, given previous research showing that more highly educated women are more likely to be drinking at problematic levels (Huerta and Borgonovi, 2010; OECD, 2015). As there were no exclusion criteria, it is possible that women who were drinking at hazardous levels and/or met criteria for AUD prior to giving birth may have been included in the study, which may have biased the results. The data used here comprise self-report measures which may suffer from such limitations as recall bias and social desirability. In particular, an unavoidable limitation is that most existing behavioural health scales, including measures of alcohol use, have not been validated for post-partum women and it is possible that social desirability concerns may lead to underreporting of hazardous use (Walker et al. 2015). The current findings should therefore be interpreted in consideration of the lack of validation of alcohol use scales for the post-partum population, albeit this is somewhat mitigated in this study, as the average time since childbirth is more than 8 years-we have not predominantly sampled a post-partum population. Notwithstanding, this is an important consideration for future studies and, as Walker et al. 2015) suggested, research could explore alternate phrasing of items on such scales, with the aim of eliciting more truthful responses.

The present study utilised existing data with a cross-sectional design to explore a previously untouched topic, with results confirming the link between traumatic experiences and drinking to cope. To allow for greater understanding of the contingencies leading to drinking as a maladaptive coping strategy and how this might unfold over time, and/or throughout multiple childbirth experiences, longitudinal research is warranted, following women pre- and post-natally. A better appreciation of the importance of individual differences in coping with adversity is much needed in this area of research, to better understand the link between traumatic childbirth experience and the hazardous use of alcohol by some women. In future studies of this area, examination of adaptive coping skills, emotion regulation 
skills and other factors such as aspects of personality may be considered to provide important contextual information surrounding how and why women might be using alcohol to cope and provide detailed information about reasons for coping, available coping repertoire and the capacity to regulate emotions. It is recommended that future studies include pathway analysis of childbirth trauma and hazardous alcohol use, guided by an appropriate conceptual model.

\section{Conclusion}

Given as many as one in four women in the sample experienced a psychologically traumatic childbirth, and that on average these women reported drinking at more hazardous levels, it is important that treatments focus on how women cope, with the aim of developing a repertoire of healthy coping strategies, so that alcohol consumption is not needed as a coping mechanism.

Acknowledgements MD thanks Ute Vollmer-Conna, Rochelle Einboden and Jess Beilharz for many inspiring and helpful discussions centred on the themes relevant to this work.

Author Contribution Both authors made substantive contributions to this study. SH designed the original study and collected the data. MD conducted literature searches and provided summaries of previous research, conducted the statistical analysis and wrote the first draft of the manuscript. Both authors contributed to and approved the final manuscript.

Funding Open Access funding enabled and organized by CAUL and its Member Institutions.

\section{Declarations}

Ethics Approval The Why Women Drink survey was considered ethically low risk and was approved by the University of New South Wales Human Research Ethics Committee (HREC; project number HC17547) and ratified by the University of Newcastle HREC (protocol number H-2017-0270).

Consent to Participate All participants provided informed consent before undertaking the survey.

Conflict of Interest The authors declare no competing interests.

Open Access This article is licensed under a Creative Commons Attribution 4.0 International License, which permits use, sharing, adaptation, distribution and reproduction in any medium or format, as long as you give appropriate credit to the original author(s) and the source, provide a link to the Creative Commons licence, and indicate if changes were made. The images or other third party material in this article are included in the article's Creative Commons licence, unless indicated otherwise in a credit line to the material. If material is not included in the article's Creative Commons licence and your intended use is not permitted by statutory regulation or exceeds the permitted use, you will need to obtain permission directly from the copyright holder. To view a copy of this licence, visit http://creativecommons.org/licenses/by/4.0/.

\section{References}

Agabio, R., Pani, P. P., Preti, A., Gessa, G. L., \& Franconi, F. (2016). Efficacy of medications approved for the treatment of alcohol dependence and alcohol withdrawal syndrome in female patients: A descriptive review. European Addiction Research, 22(1), 1-16. https://doi.org/10.1159/000433579 
Alcorn, K. L., O’Donovan, A., Patrick, J. C., Creedy, D., \& Devilly, G. J. (2010). A prospective longitudinal study of the prevalence of post-traumatic stress disorder resulting from childbirth events. Psychological Medicine, 40(11), 1849-1859. https://doi.org/10.1017/S0033291709992224

American Psychiatric Association. (2013). Diagnostic and statistical manual of mental disorders (5th ed.). American Psychiatric Association.

Aurora, P., \& Klanecky, A. K. (2016). Drinking motives mediate emotion regulation difficulties and problem drinking in college students. American Journal of Drug \& Alcohol Abuse, 42(3), 341-350. http:// ezproxy.newcastle.edu.au/login?url=http://search.ebscohost.com/login.aspx?direct $=$ true $\& \mathrm{db}=\mathrm{s} 3 \mathrm{~h} \&$ $\mathrm{AN}=116267319$ \&site $=$ eds-live

Australian Institute of Health and Welfare. (2020). National drug strategy household survey 2019. Canberra: AIHW

Ayers, S., Bond, R., Bertullies, S., \& Wijma, K. (2016). The aetiology of post-traumatic stress following childbirth: A meta-analysis and theoretical framework. Psychological Medicine, 46(6), 1121-1134. https://doi.org/10.1017/S0033291715002706

Babor, T. F., Higgins-Biddle, J. C., Saunders, J. B., \& Monteiro, M. G. (2001). AUDIT: the Alcohol use disorders identification test: Guidelines for use in primary care (2nd ed.). World Health Organization. https://www.who.int/substance_abuse/publications/audit/en

Baker, A. L., Thornton, L. K., Hiles, S., Hides, L., \& Lubman, D. I. (2012). Psychological interventions for alcohol misuse among people with co-occurring depression or anxiety disorders: A systematic review. Journal of Affective Disorders, 139(3), 217-229. https://doi.org/10.1016/j.jad.2011.08.004

Blanco, C., Xu, Y., Brady, K., Perez-Fuentes, G., Okuda, M., \& Wang, S. (2013). Comorbidity of posttraumatic stress disorder with alcohol dependence among US adults: Results from National Epidemiological Survey on Alcohol and Related Conditions. Drug and Alcohol Dependence, 132(3), 630-638. https://doi.org/10.1016/j.drugalcdep.2013.04.016

Bloomfield, K., Grittner, U., Kramer, S., \& Gmel, G. (2006). Social inequalities in alcohol consumption and alcohol-related problems in the study countries of the EU concerted action "Gender, Culture and Alcohol Problems: A Multi-national Study." Alcohol and Alcoholism. Supplement, 41(1), i2636. https://doi.org/10.1093/alcalc/ag1073

Callahan, J. L., Borja, S. E., \& Hynan, M. T. (2006). Modification of the Perinatal PTSD Questionnaire to enhance clinical utility. Journal of Perinatology, 26(9), 533-539. https://doi.org/10.1038/sj.jp. 7211562

Cerda, M., Tracy, M., \& Galea, S. (2011). A prospective population based study of changes in alcohol use and binge drinking after a mass traumatic event. Drug and Alcohol Dependence, 115(1-2), 1-8. https://doi.org/10.1016/j.drugalcdep.2010.09.011

Chandley, R. B., Luebbe, A. M., Messman-Moore, T. L., \& Ward, R. M. (2014). Anxiety sensitivity, coping motives, emotion dysregulation, and alcohol-related outcomes in college women: A moderated-mediation model. J Stud Alcohol Drugs, 75(1), 83-92. https://doi.org/10.15288/jsad.2014. 75.83

Cooper, M. L. (1994). Motivations for alcohol use among adolescents: Development and validation of a four-factor model. Psychological Assessment, 6(2), 117-128. https://doi.org/10.1037/1040-3590.6. 2.117

Cooper, M. L., Russell, M., Skinner, J. B., \& Windle, M. (1992). Development and validation of a threedimensional measure of drinking motives. Psychological Assessment, 4(2), 123-132. https://doi. org/10.1037/1040-3590.4.2.123

Cooper, M. L., Frone, M. R., Russell, M., \& Mudar, P. (1995). Drinking to regulate positive and negative emotions: A motivational model of alcohol use. Journal of Personality and Social Psychology, 69(5), 990-1005. https://doi.org/10.1037//0022-3514.69.5.990

Debell, F., Fear, N. T., Head, M., Batt-Rawden, S., Greenberg, N., Wessely, S., \& Goodwin, L. (2014). A systematic review of the comorbidity between PTSD and alcohol misuse. Social Psychiatry and Psychiatric Epidemiology, 49(9), 1401-1425. https://doi.org/10.1007/s00127-014-0855-7

Erceg-Hurn, D. M., \& Mirosevich, V. M. (2008). Modern robust statistical methods: An easy way to maximize the accuracy and power of your research. American Psychologist, 63(7), 591-601. https://doi.org/10.1037/0003-066x.63.7.591

Erol, A., \& Karpyak, V. M. (2015). Sex and gender-related differences in alcohol use and its consequences: Contemporary knowledge and future research considerations. Drug and Alcohol Dependence, 156, 1-13. https://doi.org/10.1016/j.drugalcdep.2015.08.023

Foxcroft, D. R., Smith, L. A., Thomas, H., \& Howcutt, S. (2014). Accuracy of alcohol use disorders identification test for detecting problem drinking in 18-35 year-olds in England: Method comparison study. Alcohol and Alcoholism, 50(2), 244-250. https://doi.org/10.1093/alcalc/agu095 
Freudenheim, J. L. (2019). Alcohol's effects on breast cancer in women. Alcohol research, 40(2), 11-12. https://doi.org/10.35946/arcr.v40.2.11

GBD 2016 Alcohol Collaborators. (2018). Alcohol use and burden for 195 countries and territories, 1990-2016: A systematic analysis for the Global Burden of Disease Study 2016. The Lancet, 392(10152), 1015-1035. https://doi.org/10.1016/S0140-6736(18)31310-2

Gilpin, N. W., \& Weiner, J. L. (2017). Neurobiology of comorbid post-traumatic stress disorder and alcohol-use disorder. Genes, Brain, and Behavior, 16(1), 15-43. https://doi.org/10.1111/gbb.12349

Giskes, K., Turrell, G., Bentley, R., \& Kavanagh, A. (2011). Individual and household-level socioeconomic position is associated with harmful alcohol consumption behaviours among adults. Australian and New Zealand Journal of Public Health, 35(3), 270-277. https://doi.org/10.1111/j.1753-6405.2011.00683.x

Grant, V. V., Stewart, S. H., O’Connor, R. M., Blackwell, E., \& Conrod, P. J. (2007). Psychometric evaluation of the five-factor Modified Drinking Motives Questionnaire-Revised in undergraduates. Addictive Behaviors, 32(11), 2611-2632. https://doi.org/10.1016/j.addbeh.2007.07.004

Grekin, R., \& O'Hara, M. W. (2014). Prevalence and risk factors of postpartum posttraumatic stress disorder: A meta-analysis. Clinical Psychology Review, 34(5), 389-401. https://doi.org/10.1016/j.cpr.2014. 05.003

Hasking, P., Lyvers, M., \& Carlopio, C. (2011). The relationship between coping strategies, alcohol expectancies, drinking motives and drinking behaviour. Addictive Behaviors, 36(5), 479-487. https://doi.org/ 10.1016/j.addbeh.2011.01.014

Henry, J. D., \& Crawford, J. R. (2005). The short-form version of the Depression Anxiety Stress Scales (DASS-21): Construct validity and normative data in a large non-clinical sample. British Journal of Clinical Psychology, 44(Pt 2), 227-239. https://doi.org/10.1348/014466505x29657

Higgins-Biddle, J. C., \& Babor, T. F. (2018). A review of the Alcohol Use Disorders Identification Test (AUDIT), AUDIT-C, and USAUDIT for screening in the United States: Past issues and future directions. The American Journal of Drug and Alcohol Abuse, 44(6), 578-586. https://doi.org/10.1080/ 00952990.2018 .1456545

Hobden, B., Bryant, J., Sanson-Fisher, R., Oldmeadow, C., \& Carey, M. (2017). Do rates of depression vary by level of alcohol misuse in Australian general practice? Australian Journal of Primary Health, 23(3), 263-267. https://doi.org/10.1071/py16076

Hobden, B., Bryant, J., Sanson-Fisher, R., Oldmeadow, C., \& Carey, M. (2018). Co-occurring depression and alcohol misuse is under-identified in general practice: A cross-sectional study. Journal of Health Psychology, 23(8), 1085-1095.

https://www.ncbi.nlm.nih.gov/pmc/articles/PMC3307043/

Huerta, M. C., \& Borgonovi, F. (2010). Education, alcohol use and abuse among young adults in Britain. Social Science and Medicine, 71(1), 143-151. https://doi.org/10.1016/j.socscimed.2010.03.022

James, S. (2015). Women's experiences of symptoms of posttraumatic stress disorder (PTSD) after traumatic childbirth: A review and critical appraisal. Archives of Women's Mental Health, 18(6), 761-771. https://doi.org/10.1007/s00737-015-0560-X

Kachadourian, L. K., Pilver, C. E., \& Potenza, M. N. (2014). Trauma, PTSD, and binge and hazardous drinking among women and men: Findings from a national study. Journal of Psychiatric Research, 55, 35-43. https://doi.org/10.1016/j.jpsychires.2014.04.018

Kushner, M. G., Sher, K. J., \& Beitman, B. D. (1990). The relation between alcohol problems and the anxiety disorders. American Journal of Psychiatry, 147(6), 685-695. https://doi.org/10.1176/ajp.147.6.685

Lovibond, S. H., \& Lovibond, P. F. (1995). Manual for the Depression Anxiety Stress Scales (2nd ed.). Psychology Foundation.

Maddur, H., \& Shah, V. H. (2019). Alcohol and liver function in women. Alcohol research, 40(2), 1-5. https://doi.org/10.35946/arcr.v40.2.10

McCrady, B. S., Epstein, E. E., \& Fokas, K. F. (2020). Treatment Interventions for Women With Alcohol Use Disorder. Alcohol research : current reviews, 40(2), 08-08. https://doi.org/10.35946/arcr.v40.2.08

Merrill, J. E., \& Thomas, S. E. (2013). Interactions between adaptive coping and drinking to cope in predicting naturalistic drinking and drinking following a lab-based psychosocial stressor. Addictive Behaviors, 38(3), 1672-1678. https://doi.org/10.1016/j.addbeh.2012.10.003

Messman-Moore, T. L., \& Ward, R. M. (2014). Emotion dysregulation and coping drinking motives in college women. American Journal of Health Behavior, 38(4), 553-559. https://doi.org/10.5993/ajhb. 38.4 .8

Mohr, C. D., McCabe, C. T., Haverly, S. N., Hammer, L. B., \& Carlson, K. F. (2018). Drinking motives and alcohol use: The SERVe Study of U.S. Current and Former Service Members. Journal of Studies on Alcohol and Drugs, 79(1), 79-87. 
National Health and Medical Research Council. (2020). Australian guidelines to reduce health risks from drinking alcohol. Canberra: NHMRC Retrieved from https:// www.nhmrc.gov.au/about-us/publicatio ns/australian-guidelines-reduce-health-risks-drinking-alcohol

Neumann, T., Neuner, B., Gentilello, L., Weiss-Gerlach, E., Mentz, H., Rettig, J., Schröder, T., Wauer, H., Müller, C., Schuetz, M., Mann, K., Siebert, G., Dettling, M., Joachim, M., Kox, W., \& Spies, C. (2004). Gender differences in the performance of a computerized version of the alcohol use disorders identification test in subcritically injured patients who are admitted to the emergency department. Alcoholism, Clinical and Experimental Research, 28, 1693-1701. https://doi.org/10.1097/01.ALC. 0000145696.58084 .08

Nolen-Hoeksema, S., \& Hilt, L. (2006). Possible Contributors to the Gender Differences in Alcohol Use and Problems. The Journal of General Psychology, 133(4), 357-374. https://doi.org/10.3200/GENP.133.4. 357-374

O’Donovan, A., Alcorn, K. L., Patrick, J. C., Creedy, D. K., Dawe, S., \& Devilly, G. J. (2014). Predicting posttraumatic stress disorder after childbirth. Midwifery, 30(8), 935-941. https://doi.org/10.1016/j. midw.2014.03.011

OECD. (2015). Tackling Harmful Alcohol Use: Economics and Public Health Policy. doi:https://doi.org/10. 1787/9789264181069-en

Olff, M., Langeland, W., Draijer, N., \& Gersons, B. P. (2007). Gender differences in posttraumatic stress disorder. Psychological Bulletin, 133(2), 183-204. https://doi.org/10.1037/0033-2909.133.2.183

American Psychiatric Association. (2013). Diagnostic and statistical manual of mental disorders (5th ed.). American Psychiatric Association. https://doi-org.ezproxy.newcastle.edu.au/https://doi.org/10.1176/ appi.books.9780890425596

Radomski, S. A., \& Read, J. P. (2016). Mechanistic Role of Emotion Regulation in the PTSD and Alcohol Association. Traumatology, 22(2), 113-121. https://doi.org/10.1037/trm0000068

Rehm, J. (2011). The risks associated with alcohol use and alcoholism. Alcohol research \& health : the journal of the National Institute on Alcohol Abuse and Alcoholism, 34(2), 135-143. https://www.ncbi. nlm.nih.gov/pubmed/22330211

Roos, C. R., \& Witkiewitz, K. (2016). Adding tools to the toolbox: The role of coping repertoire in alcohol treatment. Journal of Consulting and Clinical Psychology, 84(7), 599-611. https://doi.org/10.1037/ ccp0000102

Saunders, J. B., Aasland, O. G., Babor, T. F., De La Fuente, J. R., \& Grant, M. (1993). Development of the Alcohol Use Disorders Identification Test (AUDIT): WHO Collaborative Project on Early Detection of Persons with Harmful Alcohol Consumption-II. Addiction (abingdon, England), 88(6), 791-804. https://doi.org/10.1111/j.1360-0443.1993.tb02093.x

Simons, R. M., Hahn, A. M., Simons, J. S., \& Murase, H. (2017). Emotion dysregulation and peer drinking norms uniquely predict alcohol-related problems via motives. Drug and Alcohol Dependence, 177, 54-58. https://doi.org/10.1016/j.drugalcdep.2017.03.019

Slade, T., Chapman, C., Swift, W., Keyes, K., Tonks, Z., \& Teesson, M. (2016). Birth cohort trends in the global epidemiology of alcohol use and alcohol-related harms in men and women: Systematic review and metaregression. British Medical Journal Open, 6(10), e011827. https://doi.org/10.1136/bmjop en-2016-011827

Stappenbeck, C. A., Luterek, J. A., Kaysen, D., Rosenthal, C. F., Gurrad, B., \& Simpson, T. L. (2015). A controlled examination of two coping skills for daily alcohol use and PTSD symptom severity among dually diagnosed individuals. Behaviour Research and Therapy, 66, 8-17. https://doi.org/10.1016/j. brat.2014.12.013

Stewart, S. H., Zeitlin, S. B., \& Samoluk, S. B. (1996). Examination of a three-dimensional drinking motives questionnaire in a young adult university student sample. Behaviour Research and Therapy, 34(1), 61-71. https://www.ncbi.nlm.nih.gov/pubmed/8561766

Ullman, S. E., Relyea, M., Peter-Hagene, L., \& Vasquez, A. L. (2013). Trauma histories, substance use coping, PTSD, and problem substance use among sexual assault victims. Addictive Behaviors, 38(6), 2219-2223. https://doi.org/10.1016/j.addbeh.2013.01.027

van Heumen, M. A., Hollander, M. H., van Pampus, M. G., van Dillen, J., \& Stramrood, C. A. I. (2018). Psychosocial Predictors of Postpartum Posttraumatic Stress Disorder in Women With a Traumatic Childbirth Experience. Front Psychiatry, 9, 348. https://doi.org/10.3389/fpsyt.2018.00348

Walker, L. O. R. N. E. M. P. H., Gao, J. M. A., \& Xie, B. P. (2015). Postpartum psychosocial and behavioral health: A systematic review of self-administered scales validated for postpartum women in the United States. Women's Health Issues, 25(5), 586-600. https://doi.org/10.1016/j.whi.2015.05.006

Weiss, D. S. (2007). The impact of event scale: Revised. In Cross-cultural assessment of psychological trauma and PTSD. (pp. 219-238). Springer Science + Business Media. https://doi.org/10.1007/978-0387-70990-1_10 
Wilsnack, S. C. (2012). The GENACIS project: A review of findings and some implications for global needs in women-focused substance abuse prevention and intervention. Subst Abuse Rehabil, 3(Suppl 1), 5-15. https://doi.org/10.2147/SAR.S21343

Wilsnack, R. W., Wilsnack, S. C., Kristjanson, A. F., Vogeltanz-Holm, N. D., \& Gmel, G. (2009). Gender and alcohol consumption: Patterns from the multinational GENACIS project. Addiction (abingdon, England), 104(9), 1487-1500. https://doi.org/10.1111/j.1360-0443.2009.02696.x

World Health Organization. (2018). Global status report on alcohol and health 2018. Geneva: World Health Organization Retrieved from https://www.who.int/substance_abuse/publications/global_alcohol_ report/en/

Yusuf, F., \& Leeder, S. R. (2015). Making sense of alcohol consumption data in Australia. Med J Aust, 203(3), 128-130, 130e.121. https://doi.org/10.5694/mja15.00151

Publisher's Note Springer Nature remains neutral with regard to jurisdictional claims in published maps and institutional affiliations. 